\title{
Fotografia w nurcie teoriopoznawczym
}

\section{Wstęp}

Trudno znaleźć dyscyplinę wśród nauk humanistycznych, która umożliwiałaby badaczowi koncentrowanie się na obrazie nie poprzez pryzmat treści o wydarzeniach, obyczajowości, modzie, polityce, codzienności, gospodarce, historii, etc. a przede wszystkim na sposobach istnienia i rozwoju form wizualnych. Uniwersyteckie kierunki medioznawcze oscylują wokół mediów popularnych, tj. telewizja, radio, prasa, internet zwracając szczególną uwagę na sposoby dystrybucji obrazów. Z kolei na Akademiach Sztuk Pięknych media takie jak software, kamera, farba, glina, pędzel, ciało-gest analizowane są i używane pod względem zastosowania w kreacji. Media te znajdują się zatem bliżej twórców niż publiczności. „Mediów nie da się zredukować do ich form reprezentacji takich jak teatr i film, technik takich jak druk książek lub telewizja, lub do rodzajów symbolizacji takich jak pismo, obraz lub liczba. Żyją one jednocześnie we wszystkich tych postaciach"'. Brakuje języka umożliwiającego zbliżenie perspektyw teoretycznej i artystycznej czego dowodzi porównanie definicji słów „medium” i „media”, wskazujących w języku polskim na dwa różne obszary znaczeniowe, pierwszy ezoteryczny (medium to osoba kontaktująca się z zaświatami), drugi masowy ${ }^{2}$. Terminy takie jak multimedia, sztuka nowych mediów (jednocześnie nazwy kierunków studiów wizualnych na Akademiach Sztuk Pięknych) to zatem alternatywne sposoby określania dyscyplin izolujących się od konstruktu ,masowości' oraz, co w tym przypadku oczywiste, ezoteryki, ale skoncentrowanych na charakteryzującej współczesność mnogości mediów.

* Dr Micha£ Jakubowicz - Katedra Grafiki, Wydział Prawa i Komunikacji Społecznej w Filii we Wrocławiu SWPS Uniwersytetu Humanistycznospołecznego; e-mail: mjakubowicz@swps.edu.pl

${ }^{1}$ C. Pias; J. Vogl; L. Engell i in. (red), Kursbuch Medienkultur (Podręcznik kultury mediów), Stuttgart 2002, s. 10. Za: D. Mersch, Teorie mediów, Warszawa 2010, s. 8.

${ }^{2}$ Zob. M. Jakubowicz, Typy mediów, w: Teorie komunikacji i mediów, red. M. Graszewicz, M. Wszołek, Kraków 2016, s. 61-106. 
W refleksji medialnej można zatem zakreślić kilka obszarów problemowych w różny sposób tematyzujących zagadnienie. W latach 60. ubiegłego wieku Dick Higgins zaproponował koncepcję intermediów jako swoisty łącznik między tradycyjnymi dyscyplinami typu malarstwo, rzeźba, teatr, a nowymi wówczas sposobami produkcji obrazów, tu przede wszystkim fotografią, filmem, performancem. Intermedia różnią się od multimediów organizacją połączeń, „każde dzieło określa swój środek wyrazu i formę zgodnie ze swymi potrzebami. Sam pomysł staje się łatwiej zrozumiały przez to czym nie jest, niż to czym jest"3. Chodzi zatem o redukcję środków i wzajemne ich zastępowanie, nie zaś, jak występuje w programie multimedialnym, współrzędne zestawianie różnych technologii i punktów widzenia, zbliżających dzieło do fenomenu, a sposób oglądu do poznania ejdetycznego. Multimedia i intermedia wypracowały dwie różne estetyki, których charakter albo znajomość zawdzięczamy również fotografii.

Program intermediów, trochę wbrew Higginsowi poddał się akademizacji i stał jednym z przedmiotów na wydziałach Akademii Sztuk Pięknych. Co sprawia, że nie zniknął a utrwalił się w obrazie współczesnej sztuki? Zapewne wpływ na to ma nieustanna potrzeba aktualizacji, zarówno na poziomie form artystycznych wypowiedzi jak technologii, wprowadzających ciągłe i częste zmiany skutkujące nowymi uwarunkowaniami obrazu. Transfer tradycyjnych i historycznych sposobów widzenia utrwalonych przez instytucje muzeów, kolekcji i galerii sztuki nadal wymaga nowych połączeń. Intermedia pełnią zatem rolę kulturowego interfejsu między przeszłością a nieustannie umykającym teraz, utrzymują ciągłość sztuki w odniesieniu do tradycji oraz aktywności pozaartystycznych, tj. nauka, religia, gospodarka, codzienność etc.

Koncentracja na technologicznym wymiarze mediów, głównie ze względu na szybki rozwój komputerów i internetu wpłynęła na wyodrębnienie się nowych, węższych dyscyplin takich jak np. nowe media, sztuka sieci, game art, które poprzez związek z programami multimediów lub intermediów zdominowały ich powierzchowny charakter wprowadzając równie powierzchowne stylistyki. Co ciekawe metodologia artystycznych praktyk medialnych wcale nie zakłada konieczności stosowania nowej technologii czego przykładem performance czy land art. Zmiana środowiska $\mathrm{z}$ cyfrowego/wirtualnego na realne/kulturowe określa sztukę postmedialną. Zachodzące w jej ramach działania wynikają $\mathrm{z}$ wpływu mediów wizualnych ale często bez ich bezpośredniego udziału. „Postmedialne praktyki twórcze charakteryzują się podejściem interdyscyplinarnym, nie czyniąc różnicy między użyciem środków wizualnych, audialnych, interaktywnych czy wreszcie języka - tak naturalnego, jak i sztucznego, czyli języka programowania"4. Pytaniem pozostaje jak w wyżej wymienionych praktykach

${ }^{3}$ D. Higgins, Intermedia i inne eseje, wyb. P. Rypson, Warszawa 1985, s. 17.

${ }^{4}$ E. Wójtowicz, Sztuka w kulturze postmedialnej, Gdańsk 2016, s. 362. 
funkcjonuje fotografia, co bezpośrednio związane jest $\mathrm{z}$ tematem konferencji „Fotografia w mediach”, której niniejszy artykuł jest przykładem.

Tabela 01. Fotografia w mediach - ogólne zestawienie. Opracowanie własne.

\begin{tabular}{|c|l|l|l|l|}
\hline $\mathbf{l p}$ & \multicolumn{1}{|c|}{ media } & \multicolumn{1}{|c|}{ przykłady } & program fotograficzny & \multicolumn{1}{c|}{ modus } \\
\hline 1 & premedia & $\begin{array}{l}\text { światło, powietrze, } \\
\text { woda, ciało, głos, }\end{array}$ & $\begin{array}{l}\text { prefotografia, fotogra- } \\
\text { fia abstrakcyjna }\end{array}$ & $\begin{array}{l}\text { postrzeganie, odbicie, } \\
\text { cień }\end{array}$ \\
\hline 2 & media (stare) & $\begin{array}{l}\text { język, pismo, tech- } \\
\text { nologie, narzędzia, } \\
\text { instrumenty }\end{array}$ & fotomedium & $\begin{array}{l}\text { technika, sposób, kod, } \\
\text { znak, reprodukcja }\end{array}$ \\
\hline 4 & $\begin{array}{l}\text { media (nowe) } \\
\text { społeczne }\end{array}$ & $\begin{array}{l}\text { telewizja, internet, kod } \\
\text { numeryczny, virtual } \\
\text { reality }\end{array}$ & $\begin{array}{l}\text { obraz techniczny, } \\
\text { siatka }\end{array}$ & $\begin{array}{l}\text { wielość, aktual- } \\
\text { ność, algorytm, } \\
\text { przekształcalność, } \\
\text { numeryczność, przeli- } \\
\text { czalność, koniec }\end{array}$ \\
\hline sztuka
\end{tabular}

W powyższej tabeli przedstawiono cztery perspektywy w ramach których programy fotograficzne korelują z ogólnie zarysowanymi koncepcjami mediów. Programami nazwano teorie fotografii znajdujące egzemplifikacje w twórczości teoretyków i/lub praktyków, zostawiając konteksty tych teorii (związane $\mathrm{z}$ szeroko rozumianą kulturą wizualną, $\mathrm{w}$ tym antropologią wizualną, visual studies, medioznawstwem i komunikacją wizualną) poza tematem niniejszych rozważań. Jak można przypuszczać twórczość artystyczna przewyższa skromnie prezentowane przykłady, które autor przytacza głównie w celu wykazania zależności w obszarze refleksji nad mediami oraz (w tym) fotografią. Przedstawiono sfery wpływów fotografii i innych mediów w sposób możliwie ogólny, kierując się wskazówką McLuhana, że „najlepszym sposobem badania natury jakiegokolwiek medium jest badanie skutków jego działania na inne media"s.

\section{Pre-medium, fotografia kamerowa i non-kamerowa}

W naturze znajdujemy przykłady obrazów przypominających swoją specyfiką te naoczne - odbicia w tafli wody, projekcje wewnątrz jaskiń (prototypy camera obscura), ale też obrysy kształtów, możliwe do zaistnienia dzięki naturalnym

\footnotetext{
5 M. McLuhan, Wybór tekstów, przeł. E. Różalska, J. M. Stokłosa, Poznań 2001, s. 397.
} 
zjawiskom światłocienia i światłoczułości. Rośliny, skóra to światłoczułe podłoża na których zachodzi naturalne zjawisko wizualnej samoreprodukcji. Wynalazek fotografii związany z możliwością utrwalania lustrzanych obrazów, wprowadza udogodnienia komfortu pozyskiwania zdjęć, mobilność, łatwość obsługi kamery, dostępność i demokratyczność posiadania zarówno narzędzia co obrazów. „Pierwotnym jest impuls świetlny i to, co się dzieje z promieniem podczas przejścia przez otworek. Wszystko inne, począwszy od obiektywu, rysowania perspektywy oraz światłocienia, rodzaju filmu i w końcu percepcji, należy do umysłu. Narząd wzroku, jak i fotografia korzystają z jedynego znanego w przyrodzie sposobu rysowania obrazu, reprezentującego w sposób naturalny ją samą. Pojęcie obrazu jest $\mathrm{w}$ tym ujęciu równoznaczne li tylko $\mathrm{z}$ układem energetycznych śladów promieni według pewnej zasady. To, że na zdjęciu postrzegamy perspektywę, światłocień i kolor należy do cech naszego umysłu, a nie do natury. To, że na zdjęciu widzimy konia, jakim on jest lub jako metaforę, przynależy do kultury"6. Uwikłanie fotografa w proces konstruowania obrazu świata odbiera zdjęciom walor obiektywizmu na korzyść intersubiektywności. Fotografowie i publiczność potrzebują psychofizjologicznych predyspozycji i zanurzenia we wspólnie negocjowanym otoczeniu po to, by negocjacje mogły się odbywać. Jednak istnieją postawy subiektywne, tworzące wspólnie dyskurs artystyczny, polegające na oddalaniu się od znanych znaczeń, powtarzających się i nieznacznie tylko modyfikowanych wzorów w kierunku tych obrazów, które mogą zaistnieć poza sferą dyskursu. Obraz wywoływany jest bez nacisku na bycie informacją czy komunikatem. Procesowi towarzyszy pewien rodzaj zachwytu, mający większy związek z muzyką, „tonacją"” niż oferowaniem znaczeń.

Można wyróżnić dwie zasadnicze tendencje w fotografii premedialnej, które ze względów technicznych nazywam kamerową i nonkamerową. W pierwszej tendencji fotografowie eksplorują obszar wizualny zapośredniczony kamerą, niemożliwy do zobaczenia wyłącznie za pomocą zmysłu wzroku. Zdjęcia mają charakter surrealistyczny, abstrakcyjny, entropiczny odmienny od codziennego postrzegania wzrokowego mimo zastosowanych rygorystycznych środków przynależnych fotografii dokumentalnej. Sprzyjają takiemu podejściu ujęcia makro oraz małe głębie ostrości ${ }^{8}$. Tendencja ta jest wizualnie podobna choć ideowo różna względem realizacji naukowców, którzy za pomocą np. mikroskopów elektronowych, przedstawiają niecodzienne reprezentacje zwykłych obiektów. Oba działania ilustrują w istocie styk estetyki i nauki, a zatem też konieczność rozróżniania tych warstw, czemu sprzyjają pytania dotyczące autorstwa, wła-

' S. Wojnecki, Fotografia gwiazda podwójna kultury. Pisma z lat 1977-2004. Poznań 2007, s. 245.

7 Z. Dłubak, Językowe próby, rozmowę przepr. M. Jakubowicz, „Artluk” 2008, nr 3 (9), s. 46.

Z. Dłubak, Drogi Jerzy, w: J.Olek Bezwymiar iluzji. Wrocław 1995, s 3.

${ }^{8}$ Zob. Z. Dłubak, Asymetrie, online, http://faf.org.pl/image/tid/353 (dostęp10.09.2017). 
sności i wartości obrazu. Kto jest autorem zdjęcia i jakimi intencjami je określa9 . Nie zmienia to faktu, że w tendencji kamerowej eksploracja obrazów odbywa się poprzez koncentrację na aparacie i jego właściwościach odsłaniania oczom operatora tego, co niewidoczne w naturalnej percepcji. Fotografowie korzystają z szerokiego spektrum technologii, oferującej sprzęty amatorskie, profesjonalne, specjalistyczne, naukowe, medyczne, wojskowe i inne. Widać dzięki temu jak fotografia powiązana jest $\mathrm{z}$ różnymi interesami społecznymi. W tendencji artystycznej różne aparaty stosowane są poza funkcjonalnie przypisanymi celami i wzorami, to artysta określa kierunek wizualnej podróży odchodząc od utartych motywów, przedstawień i towarzyszących im schematów postrzegania. Fotograf nie tylko robi zdjęcie, ale wymyśla nowy sposób użycia danego aparatu.

Druga tendencja nonkamerowa polega na dekonstrukcji kamery i związanej z tym redukcji mechanizmów reprezentujących technologię i cywilizację. Zdjęcia powstałe bez użycia obiektywów, migawek, na samodzielnie spreparowanych przez fotografów podłożach światłoczułych są bardziej zapisami wykonywanych czynności, pustymi znakami, samoreprezentacjami niż przedstawieniami czegoś istniejącego poza obrazem. Tendencja nonkamerowa może być radykalna (kiedy to fotografowie sami konstruują instrumenty wizualne), umiarkowana (polegająca na przeprojektowywaniu mechanizmów istniejących kamer) oraz hybrydalna (ze względu na zastosowanie mechanizmów innych od kamer, np. zegara do realizacji obrazów) ${ }^{10}$. Ogląd fotografii premedialnych wymaga aktywności i twórczej percepcji, której analiza więcej może powiedzieć o publiczności niż zawartości obrazów. Zdjęcia wykraczające poza schematy wizualne, wskazują na charakter postrzegania, a nie jak zwykło się uważać, naturę zjawisk. Fotografia premedialna ewoluuje w kierunku postaw analitycznych, opisanych szerzej w kolejnym punkcie lub autopoetyckich. Zdjęcia nieposiadające określonego wzoru, nieodnoszące się do znanego schematu, oddziałujące potęgą konwencjonalnych możliwości stanowią wyzwanie dla percepcji podobne do dzieł poetyckich. „Jednym $\mathrm{z}$ wyróżników elementarnego myślenia o fotografii jest przeniesienie akcentu w procesie twórczym $\mathrm{z}$ intelektu, który nie może, jako siła sprawcza, doprowadzić do wyczerpującego poznania kreowanej sytuacji i stwarzanego obiektu, na intuicję, będącą w stanie poetycko uchwycić to, co niepoznawalne racjonalnie i logicznie" ${ }^{\prime \prime}$. Mowa tu zatem o tonacji poprzedzającej proces tworzenia się znaczeń i wpływającej na ich ostateczny kształt, jednak niesprowadzającej się do dyskursywnej analizy.

9 Zob. V. Flusser, Ku filozofii fotografii, przeł. J. Maniecki. Warszawa 2015, s. 70.

${ }_{10}$ Zob. S. Decyk, Cyklografie, online, http://fotografia.uap.edu.pl/wykladowcy/decyk-slawomir/ (dostęp 10.09.2017). Zob. P. Kula, Narzędzia i eksperymenty, online, http://pawelkula.blogspot.com/p/ zabaw.html (dostęp 10.09.2017).

${ }^{11}$ J. Olek, O..., Poznań 2013, s. 42. 
Działania określone w niniejszym akapicie jako premedialne mają charakter wcześniejszy, sygnalizowany przedrostkiem „pre”, nie tyle wobec dalej opisywanych koncepcji ale jako kategoria opisowa fotograficznych programów. W praktyce jest to obszar interesujący twórców w różnych okresach czasu. Przykładem może być „Światłoforma. Książka dla fotografii”"12 Magdaleny Poprawskiej, będąca w istocie ryzą białego papieru poddaną wielogodzinnej ekspozycji na światło przechodzące przez trzymaną w rękach artystki soczewkę (ekwiwalent obiektywu). Powstały w wyniku wypalenia obraz-rzeźba zagłębienia o kształcie odwróconego stożka, jest przykładem jak może wyglądać fotografia poza tradycyjnym procesem chemicznym, ale też w oderwaniu od standardowej symboliki doświadczeń i stereotypów.

\section{Fotografia-medium, struktury wizualne}

W ujęciu medialnym, skoncentrowanym na kamerze jako narzędziu komunikacji, fotografia wpisana jest w nurt strukturalistycznej refleksji nad językiem, która inspirowała artystów w latach 60’ i 70’. Fotografia jako przykład (cały czas) nowego medium w sztukach plastycznych była narzędziem wizualnym stosowanym na Akademiach Sztuk Pięknych (wówczas PWSSP) głównie w pracowniach Wiedzy o działaniach i strukturach wizualnych. Były to pracownie reorganizujące działania plastyczne, które wcześniej praktykowano, „a może nawet nadużywano"13. Struktura wizualna definiowana jako „czynności i konstrukcje wzrokowe, które oglądowi rzeczy przyznają rolę pierwszorzędną, lecz nie jedyną"14 ujmowana jest, przez ówczesnych teoriopraktyków, w odniesieniu do obiektów i zjawisk fizycznych, ich wpływu na percepcję oraz kreację organizacji estetycznych. Zależności między poziomami - fizycznym, psychologicznym i kreacyjnym budowane są poprzez badanie i obserwację wpływów w procesie tworzenia znaków. Struktura wizualna będąca pierwotnie przedmiotem zainteresowania w obrębie dyscyplin artystycznych, związana ze zmianami natężenia, skali i pozycji elementarnych form wizualnych jak punkt, linia, płaszczyzna, kolor wpisana jest również w konstrukcję aparatu fotograficznego. Jakość zdjęcia zależy bowiem od czułości materiału fotograficznego, proporcji kadru, nastaw głębi ostrości (pozwalających selekcjonować i przekształcać widok z trzech wymiarów do przedstawienia dwuwymiarowego) czy migawki (umożliwiającej dozować czas naświetlania). Kombinacje wymienionymi parametrami dają

${ }_{12}$ M. Poprawska, Światłoforma. Książka dla fotografii. Materiały z archiwum M. Poprawskiej, Poznań 1999.

${ }^{13}$ L. Kaćma, Zagadnienia wizualne, w: Materiały z badań prowadzonych $w$ Pracowni działań i struktur wizualnych w latach 1971-72. Wrocław 1972, s. 3.

${ }^{14}$ Tamże, s. 5. 
fotografowi względną kontrolę obrazowanej czasoprzestrzeni. Najważniejsza jest jednak w praktyce fotograficznej przekształcalność oparta na parametrach liczbowych, gwarantująca stabilność kamer jako mechanizmów, ale też powtarzalność kombinacji (nie koniecznie obrazów) i co najważniejsze możliwość stopniowalnego odchodzenia od normy, którą w psychologii percepcji określa się stałością widzenia, w kulturze wizualnej okulocentryzmem, a rzemiośle fotograficznym poprawną ekspozycją. Kamera zaprojektowana jako konsekwencja ludzkiego postrzegania umożliwia w prowadzanie przekształceń niemożliwych do zastosowania na nieuzbrojonym oku. Tak więc techniczny i kombinatoryczny charakter kamer pozwala na produkcję obrazów spoza codziennego repertuaru. Struktura wizualna dzieli się na tę znormalizowaną przez kryterium intersubiektywizmu, czyli znakową, odnoszącą się zarówno do charakteru postrzegania wzrokowego co tworzonych przez umysł pojęć oraz na tę nieznormalizowaną, będącą poza wachlarzem znanych kompozycji i nazwami.

Trwa nieustanny dialog między przedstawicielami dyscyplin artystycznych, tyczący rozbudowy repertuarów struktur znakowych. Fotografia, jak pozostałe dziedziny, umożliwia stabilizowanie lub zmiany znaczeń, hierarchizowanie, pozwala na poszukiwania znaków doskonałych, pustych, mniej lub bardziej syntetyzujących aktualne stany rzeczywistości. Fotografia nie jest wąską specjalizacją, demokratycznie rozpowszechnia postawę twórczą wśród różnych warstw społecznych, jest coraz szerzej dostępna, postępująca, prostsza w obsłudze co wpływa na tendencję dostosowywania sposobu artystycznej wypowiedzi do obranego obszaru problemowego. Pokazuje to, że fotografia na wzór tradycyjnych technik obrazowania może funkcjonować autonomicznie oraz $\mathrm{w}$ relacji do społecznie obranych celów. Kolejnym zagadnieniem jest wpływ technologii na proces powstawania znaków, przybierających różną postać zależnie od zastosowanego medium - czemu artyści starają się opierać, m.in. kultywując tradycyjne, tzw. ,umarłe media' czy ,premedia' nierelewantne z perspektywy rozwoju gospodarki, korporacji i ideologii.

Zależność między znormalizowaną i nieznormalizowaną strukturą ilustruje teoria pola równomiernego ${ }^{15} \mathrm{w}$ ramach której analizowane są różne kompozycje wizualne na siatce równomiernie ułożonych punktów, przypominających strukturę fotograficznego ziarna, tym razem doskonale regularnego. „W procesie dokumentacji wszelkie cechy obrazu (który jest zapisem widoku rzeczywistości) wynikają z cech samej rzeczywistości. A więc widoki zdokumentowane (obrazy) są ciągłe i tak jak rzeczywistość wizualna - zbudowane z nieskończonej ilości punktów. (...) Metoda streszczania widoków odpowiada podstawowej

${ }^{15}$ L. Kaćma, A. Lachowicz, Teoria pola równomiernego, w: Materiały z badań prowadzonych w Pracowni działań i struktur wizualnych w latach 1971-72. Wrocław 1972, s. 11-21. 
właściwości układu wzrokowego, a raczej jego części - oka"16. Mamy zatem w powyższym zdaniu zarysowaną perspektywę badawczą według której obraz jest obiektem wynikającym z właściwości percepcji. Obrazy i widoki działają wg reguł aktywności i pasywności pozostając względem siebie w inwersji. Pasywne układy (eksponujące samą strukturę) aktywizują układ wzrokowy dążąc do jego destabilizacji, natomiast układy znaków aktywnych skupiają wzrok uniemożliwiając interpretację wizualną. Same znaki mogą powstawać i ewoluować w sposób charakterystyczny dla samej struktury, są możliwościami zawartymi w siatce (matrycy) zbudowanej analogicznie do budowy organicznej siatkówki, jednak funkcjonującej w sposób uproszczony, na zasadach konwencji szkieletowej. Można zatem uznać, że struktury wizualne pozwalają na analizy wzorów charakterystycznych postrzeganiu i niemożliwych do uchwycenia przy prawidłowo działającym wzroku. Cechą charakterystyczną pola równomiernego (a także praktyk wizualnych opartych na mediach technicznych i cyfrowych) są jego możliwości obliczeniowe, dzięki którym powstają ciągi znaków przybierające formy tablic (kodów). „O ile ciąg symboliczny swoim charakterem upodabnia się do świata rzeczywistego, stanowiąc jego integralną część, o tyle ciągi abstrakcyjne samą swoją istotą wyróżniają się z konkretności świata. Ich konstrukcja oparta jest na sztuczności, abstrakcji cech rzeczywistości i przedstawieniu ich jako bytu odmiennego w swojej strukturze fizycznej i pojęciowej od innych przedmiotów naturalnych"17. Modelowe tablice wykonywane przy zastosowaniu metod obliczeniowych, logicznych, losowych, intuicyjnych umożliwiają ogląd ewolucji znaków, co zaświadcza o ich walorze poznawczym (pokazują zmiany między przedstawieniami, które $z$ kolei mogą być nie/relewantne, nie/referencyjne i nie/informacyjne), a przede wszystkim podlegać kryteriom estetyki.

$\mathrm{W}$ ramach tendencji fotomedialnej istnieje jeszcze pojęcie struktury pojęciowej (znanej z terminu sztuki pojęciowej), mającej swe źródło w koncepcjach semiotycznych. W teoriopraktyce artystycznej fotografia nie tyle przedstawia obiekty rzeczywistości, co obiekty percepcji i jest reprezentacją pojęć związanych z obecnymi na zdjęciach przedstawieniami. Dzięki możliwości natychmiastowego tworzenia sekwencji obrazów fotografia może być rozpatrywana jako język wizualny ${ }^{18}$, na podstawie którego zachodzi zjawisko komunikacji, będące integralną częścią projektów fotomedialnych. Praktyka wizualna fotografów związanych $\mathrm{z}$ ruchem konceptualnym pokazuje postawę tworzenia nienarracyjnych cykli zdjęciowych (kodów) lub zestawiania obrazu $\mathrm{z}$ wypowiedzią tekstową, mającą zazwyczaj ogólny charakter, niekiedy polemiczny względem

16 A. Lachowicz, Obserwacje i notacje. Warszawa 2008, s. 25.

17 Ibid., s. $29,30$.

${ }_{18}$ Zob. M. Jakubowicz, Nieustające fotografowanie. Poszukiwania w obrębie znaku i języka oraz poza systemem. W: „Seminatria Naukowe Wrocławskiego Towarzystwa Naukowego”. Wrocław 2007, nr 6 (57), s. 77. 
stanu rzeczywistości, kultury, teorii naukowych czy artystycznych co - w obu wariantach - świadczy o otwartym charakterze wizualnego przekazu. Fotografowie wrażliwi na propagandowo nastawione media kultury popularnej silnie charakteryzujące polski ustrój socjalistyczny lat 70’ we własnych wypowiedziach szeroko korzystali z tzw. form otwartych ${ }^{19} \mathrm{i}$ pozostawali wyczuleni na zamknięte formy propagandy przesyconej komunistyczną lub kapitalistyczną ideologią. Jedna $\mathrm{z}$ metod twórczych to otwieranie zamkniętych komunikatów obnażających stojącą za nimi ideologię ${ }^{20}$. Otwarte komunikaty artystyczne $\mathrm{z}$ jednej strony umożliwiają publiczności samodzielną konstrukcję znaczeń i związane są z doświadczaniem wolności, z drugiej strony budzą konfuzję w społeczeństwach nawykłych do form zamkniętych, wykluczając z obiegu artystycznego środowiska nastawione na nieintelektualną rozrywkę, przede wszystkim te pozaakademickie, pozauniwersyteckie.

Pojęciowy charakter fotografii wymaga nieustannej weryfikacji i bardziej odnosi się do pytań: co to znaczy?, co to komunikuje?, niż co fotografia przedstawia? Sytuacji nie ułatwia dokonany przez Charlesa Pierce’a podział znaków na indeksy, ikony i symbole wedle którego wielu semiotyków skłonnych jest postrzegać zdjęcia za przykłady indeksów (wskazujących na pojęcia za pomocą konkretnych fragmentów/elementów), przyznając jednocześnie, że fotografie posiadają cechy ikoniczne (streszczają realistyczny obraz do uproszczonej formy) i symboliczne (wymagają znajomości znaczeń kulturowych). Obie przedstawione struktury: wizualna i pojęciowa nachodzą na siebie. Wzory powstające dzięki zastosowaniu pola równomiernego mogą być asemantyczne, wieloznaczne i jednoznaczne zależnie od przyjętej konwencji, mogą być zatem stosowane $\mathrm{i}$ interpretowane $\mathrm{w}$ odniesieniu do pojęć jak również kształtowane wizualnie (na zasadzie tworzenia wzorów), albo cyfrowo poza obrazem i znaczeniem.

\section{Media cyfrowe, obrazy techniczne i fotorealistyczne}

Interesujące jest $w$ jaki sposób fotografia wpisująca się w nurt mediów cyfrowych rozwija struktury wypracowane $w$ ramach mediów analogowych, co również przekłada się na podział między starymi i nowymi środkami. Ważne są tutaj przewartościowania i sytuacje graniczne wynikające z zastosowania cyfrowej technologii oraz otwarcia na nowe dziedziny twórcze. Istotne jest także pojęcie obrazu technicznego, rozumianego jako sposób obrazowania wynikający $\mathrm{z}$ interpretacji tekstów naukowych ${ }^{21}$. Z jednej strony fotografia dzięki obecności

19 O. Hansen, Zobaczyć świat, Warszawa 2005, s. 28-34.

20 M. Jakubowicz, Medium na białym tle, Wrocław 2008, s. 21-25.

${ }^{21}$ V. Flusser, Ku filozofii fotografii, przeł. J. Maniecki. Warszawa 2015, s. 49. 
nowych mediów przenika (jako podstawowy kod) do innych technik obrazowania, a więc można tu mówić o otwarciu sytuacji twórczej (konsekwencją jest zainteresowanie fotografów grafiką, filmem, drukiem $3 \mathrm{~d}$ ale też performancem, teatrem, etc.) z drugiej strony fotografowie pracują przy nieustannej świadomości końca fotografii. Technologicznie jest to koniec fotografii analogowej, która staje się coraz bardziej wyszukaną aktywnością. Podchodząc do zjawiska semiotycznie, fotografia upodabnia się do grafiki komputerowej tak, że trudno określić stopień komputerowej ingerencji. Ujmując zagadnienie końca fotografii od strony obliczeniowej sytuacja również się zmienia. Fotograficzne ziarno zastąpione cyfrowym pikselem operuje policzalną siatką punktów, których kombinacje mnożą się wg niewyszukanego wzoru. Można zatem obliczyć zakres wszystkich obrazów jakie są możliwe do wygenerowania dla danej wielkości matrycy, co więcej, wygenerować fotograficzną rzeczywistość, która, jak się okazuje, nie ma wiele wspólnego ani z fizyczną realnością, ani z rzeczywistością doświadczalną wzrokowo ${ }^{22}$. Rzeczywistość wirtualna powstająca na bazie siatki stricte fotograficznej, czyli bitmapy, to ogromny zbiór możliwości, wśród których obrazy odpowiadające wizualnym strukturom poznawczym człowieka (charakteryzującym się spójnością i ciągłością uporządkowania) to zdecydowana mniejszość przeciwstawiona entropii wizualnego szumu.

Wśród działań twórczych z zakresu fotografii cyfrowej można wyodrębnić dwa typy, pierwszy polegający na symulacji fizycznej obecności obiektów w świecie wraz ze wszelkimi konsekwencjami jak figuratywność przedstawień, sugestywność, intuicyjność, trójwymiar oraz drugi typ polegający na eksploracji szumu, kodu, wszelkiego rodzaju niespójności, konwencjonalnego charakteru języka wizualnego, niewymagającego referencyjności. Wśród ogromnej ilości obrazów, jakie mogą powstać w cyfrowym środowisku, nieliczne tylko odnoszą się do figuracji i symboliki znanej z historii tworzonych przez człowieka obrazów. Fotografia cyfrowa ujawnia swój konwencjonalny charakter jako kod podatny na przekształcenia, umożliwiający tworzenie map bitów. Cyfrowe zdjęcia-mapy przybliżają zatem asemantyczne wzory wizualności posiadającej dwie zasadnicze cechy: skończoności (z punktu widzenia matematyki fotografia jest policzalna) i nieskończoności (z punktu widzenia jednostkowego doświadczenia). Fotografowie mogą śmiało przenosić swoje wizualne kompetencje na inne obszary twórcze, przekraczając istnienie skończonego kodu, którego modyfikacje wymagają bardziej kompetencji informatycznej niż wizualnej czy artystycznej. Naturalne są też powroty fotografów do technologii analogowej, która paradoksalnie, jak się okazuje, posiada dłuższy termin ważności od sprzętów cyfrowych, wymagających nieustannych aktualizacji i udoskonaleń, ukierunkowana jest na realne

22 Zob. M. Jakubowicz, K. Moszczyński, Generowanie obrazów, w: Badanie i projektowanie komunikacji 4. red. A. Siemes, M. Grech, Kraków 2015, s. 135-152. 
inscenizacje zdjęć, oferuje matryce zawierające nierównomierne ułożenie ziaren (i potencjalnych informacji), dzięki czemu policzalność obrazu jest względna. Nie trudno zatem zauważyć, że w perspektywie nowych mediów następują zmiany strukturalne, wymagające dokładniejszego opisu.

Połączenie kamery z komputerem, digitalizacja technik specjalnych tj. solaryzacja, cyjanotypia, negatyw, a także zastosowanie kamery jako narzędzia komputerowego oprogramowania, zdecydowanie zwiększa wpływ obróbki obrazu na efekt finalny. Można zatem mówić o powrocie stylistyki piktorialnej (głównie w wydaniu tzw. internetowego folkloru, grafiki komputerowej, ilustracji), kiczu (będącego nie rzadko wyrazem strategii subwersywnych), kolażu i fotomontażu, ale przede wszystkim dostępności stylistyki fotorealistycznej, polegającej na komputerowym generowaniu obrazów przypominających fotografie - co ujawnia zasadniczy potencjał w temacie inscenizacji ${ }^{23}$. Dzięki zastosowaniu cyfrowej obróbki obrazów fotografia zyskuje na sugestywności i fantastyce przedstawień, traci jednak wymiar procesualny wymagający obecności modeli i rekwizytów - tak charakterystycznych dla strategii analogowych. Fotograficzna struktura wizualna, której zadaniem jest normalizacja przedstawień, czyniąc je podobnymi do postrzeganych wzrokowo przedmiotów w obrazowaniu cyfrowym osiąga status priorytetowy, to znaczy, że obraz przedstawia obiekty w sposób wyidealizowany. Możliwe są reprezentacje nieposiadające desygnatów, innymi słowy ,znaczonego'. W dążeniu do przedstawień idealnych, paradoksalnie, okazuje się, że niedoskonałości są wartością, gdyż dodają obiektom cech realności.

$\mathrm{W}$ fotografii rozumianej jako nowe medium wyróżniamy zatem trzy procesy powstawania zdjęć, dysponujące trzema matrycami i to one wspólnie wpływają na tonacje powstających znaczeń. Jako pierwsza jest fotografia analogowa (oferująca współcześnie całe arsenały korpusów, obiektywów i materiałów światłoczułych o ogromnej skali odwzorowania w porównaniu z wciąż aspirującą w tym względzie technologią cyfrową), charakteryzująca się nieregularnym punktem matrycy, tzw. ziarnem oraz zakotwiczeniem w realności, potwierdzanym na każdym etapie procesu fotograficznego od momentu obecności modela i fotografa, kamery wykonanej na użytek fotografa, kliszy będącej zarówno matrycą wizualną jak i realnie istniejącym przedmiotem po zdjęcie i samą publiczność. Opozycją fotografii analogowej jest komputerowy render posługujący się stylistyką fotorealistyczną i udający fotografię. Cyfrowe rendery dysponują siatką wektorową, przez co są łatwe do skalowania bez straty jakości, cechują się gładkimi, jednolitymi powierzchniami, których zestawienia nawet w najmniejszych detalach wynikają z obliczeń składowych koloru, kształtu, natężenia, pozycji. Zasadniczą inspiracją do tworzenia renderów jest obrazowanie fotograficzne. Rendery powstają na podstawie zdjęć i zastępują zdjęcia, jednak metoda ich

${ }^{23}$ S. Wojnecki, Fotografia gwiazda podwójna kultury. Pisma z lat 1977-2004. Poznań 2007, s. 245. 
powstawania bardziej od pracy fotografów przypomina strategie renesansowych malarzy, którzy posługiwali się przy odwzorowaniu perspektywy i skali camera obscurą. Różnica przejawia się w stosunku do fizycznej realności: może ona być, może jej nie być, może ona dopiero nastąpić. Tak więc do wykonania renderów nie potrzeba realnych bytów, nie potrzeba znaczonego w tym stopniu, jak to jest praktykowane w fotografii. Przykładem są tutaj rendery fantastycznych miast istniejących wyłącznie na obrazach, ale nie w fizycznej realności. Rendery to projekty bliższe pojęciom nie związanym $\mathrm{z}$ fizyczną realnością tylko twórczą kreatywnością, co, jak powiedziano, zbliża tę technikę do malarstwa, projektowania, czyniąc związek z fotografią i jej klasycznym procesem przygodnym oraz powierzchownym. Fotograf za pomocą zdjęć zmienia obserwowany świat, projektant obrazów fotorealistycznych tworzy go na nowo.

Trzeci proces charakterystyczny współczesnej fotografii dotyczy zdjęć cyfrowych, powstających przy współudziale realnych i wirtualnych obiektów. Jedne i drugie są wzajemnie zastępowalne nawet w najmniej oczekiwanych miejscach. Przede wszystkim fotograf zastępowany jest przez operatora kamery, która w niektórych przypadkach działa zupełnie automatycznie, tak więc potrzebuje tylko osoby uruchamiającej mechanizm i go wyłączającej. Poetyka autoportretu pozwala tworzyć fotografie samym modelom rozwijającym sferę autokreacji. Natomiast fotografia przemysłowa jest przykładem jak zdjęcia i filmy mogą funkcjonować poza publiczną prezentacją. Obraz funkcjonuje jako emisja w której pierwowzorem nie jest negatyw tylko algorytm opisujący każdy z kwadratowych pikseli cyfrowej matrycy. Kompetencja czytania negatywów zastąpiona zostaje więc kompetencją czytania algorytmów. Fotografia cyfrowa jest hybrydalna, częściowo pozostaje w świecie realnych bytów, w znacznej mierze przenosi się jednak w modelowy obszar projektowania, twórczości i fikcji.

\section{Fotografia społeczna}

Społeczeństwo tworzy funkcjonalną strukturę obrazu ukierunkowaną na człowieka w wymiarze egzystencjalnym oraz relacyjnym. Spojrzenie fotografa pozostawia intencjonalne ślady notowane $\mathrm{w}$ formie zdjęć. Ślady mogą być różne w formie, mogą odnosić się mniej lub bardziej do znaczonych obiektów realności i pojęć. W transmisyjnym modelu zdjęcia wymagają odszyfrowania (dekodowania), natomiast w modelu komunikacji społecznej zastosowane znaki sterują „mechanizmem orientacyjnym i negocjacyjnym, służącym do wytworzenia i zabezpieczenia systemu społecznego"24. Mamy zatem do czynienia $\mathrm{z}$ relacją model - fotograf - publiczność w której występuje dynamiczny podział

${ }^{24}$ M. Fleischer, Konstrukcja rzeczywistości 2. Wrocław 2008, s. 25. 
ról i kompetencji. Dla ilustracji zobaczmy jak ta relacja funkcjonuje względem pytań zbudowanych na podstawie trzech elementów znaku: desygnatu, formy i znaczenia. Kto i w jakim stopniu określa, co ma pojawić się na zdjęciu, jak ma wyglądać zdjęcie oraz co ono znaczy - model, fotograf czy publiczność? Okazuje się, że podział nie jest równy i zawsze zależny od negocjacji. Nie jest to zatem statyczna struktura tylko dynamiczna relacja. Każde zdjęcie zależne jest od sytuacji społecznej o wiele szerszej niż przestrzeń, w której znajduje się fotograf naciskający spust migawki. Ważna jest relacja oraz wynegocjowany w jej dynamicznych ramach podział kompetencji. Na przykład fotograf decyduje, co ma pojawić się na zdjęciu (komponuje obiekt w kadrze i wyodrębnia za pomocą głębi ostrości), publiczność określa sposób wyglądu (współtworzy fotografowaną przestrzeń: buduje domy, ulice, szyje ubrania), a model tworzy znaczenie zdjęcia (fotograf przeglądając wglądówki wyszukuje tych, na których model komunikuje w sposób najbardziej intrygujący. „Reagujesz na zdarzenia i jednocześnie uczysz się, co znaczą - dla ciebie. Co oznacza gest, co czujesz na widok jakieś osoby. Pogłębiasz zdolność odczytywania tych znaków”25). W ten sposób fotografowie uliczni uczą się obserwować i interpretować otaczającą kulturę - przestrzeń publiczną, a w niej zachowania ludzi (aktorów społecznych). W ostatecznej mierze są niezależni, bo to oni dokonują decydujących wyborów. Jednak ta relacja może wyglądać zupełnie inaczej w fotografii portretowej, kiedy to model decyduje pojawić się na obrazie, respektuje publiczne wymagania dotyczące autoprezentacji i występuje w określonym stroju (lub bez - zależnie od publiczności) i pozie, a od fotografa oczekuje przekształcenia jego tożsamości w wizerunek, np. osoby zamożnej, poważnej, nobliwej. Można zatem mówić o scenariuszach zachowań kształtujących różne relacje, gwarantujące ich przewidywalność. W ramach scenariuszy zachowań działają twórcy koordynujący przedstawiony w uproszczeniu model relacyjny, którymi są konceptualni artyści, reżyserzy, dyrektorzy artystyczni, agenci, kuratorzy, zatem osoby określające zasady pracy i nierzadko ostateczny wygląd obrazów, czego przykłady znajdziemy zarówno w fotografii artystycznej co reklamowej. Przykładem jest Gregory Crewdson wymyślający swoje zdjęcia i reżyserujący je przy udziale ekipy składającej się - na wzór filmowej - z operatora aparatu, postproducentów, modeli i kuratorów rozpowszechniających efekty jego pracy ${ }^{26}$. Crewdson nie nastawia kamery i nie naciska na spust migawki tylko reżyseruje obraz, którego jest ostatecznie autorem. W dynamicznej strukturze relacyjnej dla każdej strony ważne jest bycie na miejscu, odpowiedzialność w realizacji

${ }^{25}$ J. Meyerowitz, wypowiedź w filmie: Ch. Dunn, Nowojorska ulica w obiektywie. Stany Zjednoczone 2013, 5'00".

${ }^{26}$ Zob. G. Crewdson, Beneath the Roses, online, http://www.gregorycrewdsonmovie.com/ (dostęp: 10.09.2017). Ch. Cotton, Fotografia jako sztuka współczesna, Kraków 2010, s. 67,68. 
powierzonych zadań, samorealizacja nastawiona na rozwój i poczucie wolności, obserwacje, wnioskowania.

Istotna jest też umiejętność posługiwania się ekwiwalentami modeli, fotografa, publiczności. Model nie mówi (zdjęcie jest nieme, ale też sam model może być artefaktem lub elementem natury) - symbolizuje coś za pomocą performatywności i relacji z publicznością oraz estetyką/technologią kontrolowaną przez fotografa. Zaistniała relacja koordynowana jest przez reżysera reprezentującego politykę, czyli podejście ideowe i wartościujące. Zdarza się, że tak złożone dzieła wykonane są przez jednego twórcę układającego wszystkie znaczenia w spójną całość, bywa, że nad realizacją pracują zespoły, albo dzieło jest w którymś miejscu nieokreślone, dzięki czemu może być przekształcane (niekiedy wykorzystywane) po raz kolejny i jako kolejny obiekt komunikacyjny. Co ciekawe literatura przedmiotu nie operuje zbyt wieloma opisami scenariuszy zachowań, np. artystów konceptualnych, fotografów mody, zadowalając się budowaniem kolejnych pięter interpretacyjnych dla samych dzieł, czego przykładem historia sztuki w ramach której określane są nowe związki znaczeniowe zdjęć z tradycją, filozofią etc. W samych działaniach twórczych nie chodzi o posługiwanie się znanymi scenariuszami, tylko takie ich modyfikacje, które pozwolą na wyodrębnienie nowych jakości.

Warto sięgnąć tutaj do strategii codzienności, która nadaje charakter fotografii amatorskiej, czyniąc z niej podstawowy i jednocześnie niezwykle powszechny sposób funkcjonowania. „Normalnie amator jest określany jako niedojrzały artysta, ktoś, kto nie potrafi lub nie chce wspiąć się na wyżynę profesji. Ale na polu praktyki fotograficznej jest właśnie wprost przeciwnie, to amator stanowi o wcieleniu się profesjonalności: gdyż to on znajduje się najbliżej noematu Fotografii”"27. W recepcji amatorskiej istnieje specyficzna więź między modelem, fotografem a publicznością. Są to relacje rodzinne, przyjacielskie, towarzyskie zawłaszczające przestrzeń publiczną do kształtowania prywatności. W tradycyjnym modelu, który dziś może zdawać się już nieco archaiczny, pokazywanie zdjęć związane jest z przyjmowaniem do grona przyjaciół, przedstawianiem historii i tradycji rodzinnych, a nade wszystko z rozmową. Jeśli jednak fotografia prywatna przeniesiona zostanie do przestrzeni publicznego oglądu, gdzie określone więzi rodzinne i przyjacielskie nie funkcjonują, to okazuje się, że performatywy przestają być relewantne, natomiast obecne na zdjęciach znaczenia publiczne działają ze zwiększoną siłą. Wraz z utratą prywatności przerwana zostaje lub osłabiona więź. Umniejszają się możliwości prowadzenia dialogu na podstawie fotografii obcych ludzi, bardziej znaczące są wówczas elementy kulturowe, związane z pytaniami jak ludzie się noszą, zachowują, jak żyją, jak się przedstawiają? Konieczne jest też wypełnienie luki w dialogu za pomocą

${ }^{27}$ R. Barthes, Światło obrazu. Uwagi o fotografii. Warszawa 1996, s. 167. 
tekstu, podpisów lub opisów ukierunkowanych na performatywy w innym razie prywatne wizerunki ulegają upolitycznieniu i nabierają znaczeń bardziej ogólnych, np. Polaków żyjących na początku XXI w, albo zabawy młodzieży, etc. Zmiana znaczeń wynikająca z utraty więzi między publicznością i osobami występującymi na zdjęciach była elementem programu Archeologii fotografii Jerzego Lewczyńskiego, oferującej ogląd estetyczny i zarazem zapośredniczony w technologii fotograficznego medium. Artysta przedstawiał na wystawach anonimowe zdjęcia znalezione w powojennej Polsce. W swoich wypowiedziach uwagę skupiał zarówno na utraconych wizerunkach i społecznych wartościach co na ulotności fotograficznej materii. „Zawsze podziwiałem to, co nazywałem ciałem fotografii, a co demonstrowało się podkreśleniem specyfiki tworzywa. Jak więc dbać o przesadną czystość czy estetykę tworzywa, gdy dotykając starych fotografii czuję i widzę ślad tej, często sponiewieranej przeszłości lub ślady dotyku dłoni i oczu?"28. Dla porównania amerykańska fotografka Susan Meisalas zbiera i archiwizuje fotografie rodzinne Kurdów, starając się zachować i rozpowszechniać ich tożsamość narodową za pomocą prywatnych i anonimowych wizerunków ${ }^{29}$. Zdjęcia Meisalas w odróżnieniu od realizacji Lewczyńskiego zachowują surowy wygląd fotografii codziennej, artystka nie skupia się na artefaktach i słabej kondycji fotograficznego medium tylko z premedytacją używa ich jako „surowca” w kuratorskim projekcie politycznym, przedstawiającym naród $\mathrm{z}$ kraju, którego terytorium podzielone jest między Turcję, Irak, Iran i Syrię.

Widać z powyższych przykładów, że relacja model - fotograf - publiczność koreluje $\mathrm{z}$ warstwą słowno-tekstową. W niniejszym ujęciu fotografia wymaga dialogu uzupełniającego performatywny charakter zdjęć. Bez rozmowy ukierunkowanej na pytania kto/co? kiedy? jak? gdzie? dlaczego? zdjęcie może być wieloznacznie interpretowane i nie dawać publiczności komfortu sensowności. Trzeba zatem rozróżnić wskazówki ukierunkowane na performatywne dookreślanie tego, czego fotografia jako znak nie przedstawia, np. nazw, dat, wielkości, przestrzeni pozakadrowej etc., ale też dialogi dotyczące kulturowych pojęć do których odnoszą się zdjęcia, tu chodzi o dyskusje naukowe, społeczne, etyczne. Niezależnie od powyższego interpretujemy estetykę dotyczącą zastosowanych i niezastosowanych do realizacji zdjęć środków/technologii oraz idee związane z pytaniami po co, dla kogo i w jakim celu zdjęcia są pokazywane. Co ciekawe ideologiczne podejścia kuratorskie mają wypracowany kolejny zestaw scenariuszy wizualnych wg których obrazy są interpretowane i dobierane.

${ }_{28}$ J. Lewczyński, Fotografie i rzeczy znalezione. Wrocław 2007, s. 3.

${ }_{29}$ Zob. S. Meisalas, Kurdistan, online, http://www.susanmeiselas.com/archive-projects/kurdistan/\#id=intro (dostęp 10.09.2017). 
Między warstwami wizualną i dialogiczną istnieje dynamiczna relacja, która traci swoją elastyczność w wyniku zastąpienia dialogu (rozmowy) tekstem pisanym. Zmiana ta dotyczy możliwości interakcji tak charakterystycznej dla dialogu przebiegającego w parze lub grupie interlokutorów, która to możliwość interakcji w tekście zostaje poważnie nadwyrężona lub po prostu zatracona. Dialog przemieniony w tekst związany jest także $\mathrm{z}$ autoprezentacją i manifestacją intencji (konieczną do zwrócenia na siebie uwagi, wynikającą z obawy pominięcia) a także stronniczością (bycie po różnych stronach komunikacji zastępuje bycie razem i wspólną wymianę myśli). Taka forma dialogizowania zastępowanego autoprezentacją i manifestacją idei marginalizującymi ujęcia estetyczne, kulturowe czy performatywne, charakterystyczna jest dla przestrzeni publicznej, w której wszystko może stać się komunikatem.

Wracając jednak do przestrzeni prywatnej warto sprawdzić jak relacja model - fotograf - publiczność pracuje w strukturze czasu. Model pojawiający się przed obiektywem aparatu operuje czasem przyszłym (zadaje pytanie jak będę wyglądał na fotografii), fotograf pracuje w teraźniejszości (interpretuje to, co jest na wizji), publiczność zaś operuje czasem przeszłym (wskazuje: on tam był, istniał realnie). Jak widać w tym klasycznym układzie charakterystycznym fotografii codziennej i amatorskiej technologiczna szybkość wykonywania zdjęć graniczy z ciągłością czasu, która w dynamicznej relacji może podlegać negocjacjom. Mówiąc kolokwialnie czas może się uginać i jest elementem ideologii. Struktura wizualna czasu przeszłego, operuje symbolami ukierunkowującymi uwagę na minione zdarzenia, prezentowanymi w sposób możliwie najbardziej precyzyjny, czego przykładem są policyjne kroniki i fotografia dokumentalna. Strukturę czasu teraźniejszego reprezentuje fotografia codzienna, notatnikowa i reporterska (w których najistotniejsze są bieżące fakty), natomiast struktura czasu przyszłego uprawiana jest przez fotografów kreacyjnych, imageowych, reklamowych, których zdjęcia nie przedstawiają aktualnych czy minionych zdarzeń tylko te wyidealizowane, potencjalne, mogące dopiero zaistnieć w realności przy współudziale publiczności. Nakładanie się wzajemne modelu relacyjnego z gramatyką czasu wymaga negocjacji i ustalenia spójności wizerunku. Może być również inspiracją do badań wpływu odmiennych konceptualizacji czasu na obraz.

Prywatność fotografii codziennej będąca $\mathrm{z}$ jednej strony udziałem niezwykle powszechnym, $\mathrm{z}$ drugiej zaś indywidualnym buduje warstwę doświadczeń idiosynkratycznych, charakteryzujących indywidualne światy przeżyć, doświadczeń i emocji. Roland Barthes określił te doświadczenia jako punctum, czyli zwracanie uwagi na jakiś element zdjęcia z trudnych do zidentyfikowania, a też nie zawsze ważnych do szerszego komunikowania, powodów. „Bardzo często punctum jest ,szczegółem', to znaczy jakimś konkretnym przedmiotem. 
Ale przytoczyć przykłady punctum to znaczy w pewnym sensie odsłonić się"30. Doświadczenia idiosynkratyczne charakteryzują fotografię pozwalającą na przypominanie sobie tego, co było, we własnych doświadczeniach i pamięci ale też doświadczeniach zapomnianych, powracających jako emocja podczas konfrontacji z fotograficznym obrazem, przedstawiającym jakiś charakterystyczny jednostkowo grymas twarzy, uczesanie, układ sznurówek, czy chmur. To odnoszenie fotografii do własnych doświadczeń związane jest z podobieństwem mechanizmów kształtujących obrazy fotograficzne i wzrokowe oraz akceptacją znakowej umowności zdjęć. Społeczna aprobata dotycząca kanonu realizmu i referencyjności jest niezmienna, mimo że zmieniają się technologie, a wraz z nimi kryteria wizualne i ideologiczne tego, co jest realistyczne i do jakiej rzeczywistości się odnosi. Współcześnie istotna jest natomiast różnica oparta na metodzie powstawania obrazów, które mogą być wynikiem pracy fotografa w oparciu o ustandaryzowany (referencyjno-performatywny) mechanizm kamery lub w oparciu o cyfrową matrycę zbliżającą zdjęcie do ilustracji (pojęć, idei).

Istnieje jeszcze zjawisko przywoływanych scenariuszy kuratorskich, związanych $\mathrm{z}$ funkcją koordynatora procesu negocjacyjnego, wprowadzającego perspektywę określonego programu społecznego. Programy komunikacji społecznej stanowią zasadniczy paradygmat i nadają ramy sposobom definiowania samej fotografii. Przykładowo program religijny działający wg rozróżnienia na wiarygodne i niewiarygodne buduje zupełnie inną relację od tej reprezentowanej przez program sztuki w którym kluczowy jest pewien rodzaj zachwytu, wstrząsu estetycznego, zrozumienia doświadczonego w ramach kryteriów estetycznych. Programy wyróżnione przez komunikację społeczną są ogólne i w praktyce nachodzą na siebie.

Tab. 02. Tabela programów komunikacji społecznej i ich modusów na przykładzie fotografii ${ }^{31}$.

\begin{tabular}{|l|l|l|}
\hline \multicolumn{1}{|c|}{ Program } & \multicolumn{1}{|c|}{ modus } & \multicolumn{1}{c|}{ przykład } \\
\hline religia & wiarygodnie/niewiarygodne & $\begin{array}{l}\text { jest nie/wiarygodnym obrazem } \\
\text { rzeczywistości }\end{array}$ \\
\hline gospodarka & tanie/drogie & pokazuje to, czego nie/można kupić \\
\hline medycyna & chore/zdrowe & $\begin{array}{l}\text { pokazuje to, co niewidzialne, umożliwia } \\
\text { porównanie }\end{array}$ \\
\hline prawo & prawdziwe/nieprawdziwe & $\begin{array}{l}\text { pokazuje nie/prawdziwy obraz } \\
\text { rzeczywistości }\end{array}$ \\
\hline wojsko & efemeryczna/niezniszczalna & utrwala i uwiecznia rzeczywistość \\
\hline
\end{tabular}

30 R. Barthes, op. cit., s. 77.

31 Por. M. Fleischer, op. cit., s. 39. 


\begin{tabular}{|l|l|l|}
\hline \multicolumn{1}{|c|}{ Program } & \multicolumn{1}{c|}{ modus } & \multicolumn{1}{c|}{ przykład } \\
\hline polityka & obiektywna/nieobiektywna & pokazuje znane obiekty na znanych tłach \\
\hline administracja & oznaczone/nieoznaczone & identyfikuje i uzupełnia etykietki \\
\hline edukacja & znane/nieznane & $\begin{array}{l}\text { umożliwia poznawać rzeczywistość bez } \\
\text { ograniczeń czasu i przestrzeni }\end{array}$ \\
\hline nauka & tak samo/inaczej & pozwala zobaczyć świat w inny sposób \\
\hline humanistyka & znaczące/bez znaczenia & pokazuje to, co niewidoczne \\
\hline sport & ekstremalne/nieekstremalne & $\begin{array}{l}\text { pokazuje momenty nieuchwytne do } \\
\text { zobaczenia }\end{array}$ \\
\hline rozrywka & możliwe/niemożliwe & jest grą przemieniającą prawdę w fikcję \\
\hline sztuka & piękne/brzydkie & zamienia brzydkie w piękne \\
\hline technika & poprawne/niepoprawne & jest nie/doskonała \\
\hline & &
\end{tabular}

\section{Podsumowanie}

Opisane w powyższych czterech punktach programy fotografii nie wyczerpują w pełni tematu. Wszystkie jednak posługują się rozróżnieniem na kanoniczne sposoby tworzenia obrazów oraz transformacyjne, polegające na przekształcaniu fotograficznych kodów, zarówno tych technologicznych co wynikających z przyjętych metod twórczych. Fotografia w mediach ma zatem dwa oblicza to znane, rozwijające specyfikę percepcji wizualnej oraz drugie, możliwe do zaistnienia dzięki kombinatorycznemu charakterowi kamerowych ustawień. Relacyjna interpretacja procesu projektowego scala wyżej wymieniony podział, uznając że każdy obraz niezależnie od stopnia skomplikowania i charakteru podlega negocjacjom i może być zastosowany w komunikacji. W ten sposób fotografia rozumiana jako całokształt obrazów realizowanych przy pomocy kamer zmienia się o kolejne możliwości wizualne, którym nadawane są określone znaczenia. Umowność fotograficznych znaczeń współtworzonych przez modeli, fotografów i publiczność jest propozycją możliwie ogólną i prawdopodobnie optymalną dla zastosowania zdjęć w komunikacji wizualnej. Łączy ona podejścia związane z planowaniem, realizacją i dystrybucją obrazów. Podział na znane i nieznane $\mathrm{w}$ fotografii odnosi się do dychotomii wspólnotowego i subiektywnego doświadczania obrazów. Programy komunikacji społecznej pozwalają na prognozowanie przebiegu komunikacji wizualnej, natomiast percepcja ukierunkowana na subiektywne światy przeżyć jest w znacznej mierze nieprzewidywalna i przez to można ją uznać za twórczy element opisywanego procesu, gwarantujący szczególne miejsce i rolę fotografii amatorskiej oraz wszelkiej innej wynikającej z postaw subiektywnych. 


\section{Bibliografia:}

R. Barthes, Światło obrazu. Uwagi o fotografii, Warszawa 1996.

Ch. Cotton, Fotografia jako sztuka współczesna, Kraków 2010.

Z. Dłubak, Językowe próby, rozmowę przepr. M. Jakubowicz, „Artluk” 2008, nr 3 (9).

Z. Dłubak, Drogi Jerzy, w: J.Olek Bezwymiar iluzji, Wrocław 1995.

M. Fleischer, Konstrukcja rzeczywistości 2, Wrocław 2008.

V. Flusser, Ku filozofii fotografii, przeł. J. Maniecki, Warszawa 2015.

V. Flusser, Writings, trans. Erik Eisel, Minneapolis 2002.

O. Hansen, Zobaczyć świat, Warszawa 2005.

D. Higgins, Intermedia i inne eseje, wyb. P. Rypson, Warszawa 1985.

M. Jakubowicz, Nieustające fotografowanie. Poszukiwania w obrębie znaku ijęzyka oraz poza systemem, W: „Seminatria Naukowe Wrocławskiego Towarzystwa Naukowego", Wrocław 2007 nr. 6 (57).

M. Jakubowicz, Medium na białym tle.Wrocław 2008.

M. Jakubowicz, K. Moszczyński, Generowanie obrazów, w: Badanie i projektowanie komunikacji 4. red. A. Siemes, M. Grech, Kraków 2015.

M. Jakubowicz, Typy mediów, w: Teorie komunikacji i mediów, red. M. Graszewicz, M. Wszołek, Kraków 2016.

L. Kaćma, Zagadnienia wizualne, w: Materiały z badań prowadzonych w Pracowni działań i struktur wizualnych w latach 1971-72. Wrocław 1972.

L. Kaćma, A. Lachowicz, Teoria pola równomiernego, w: Materiały z badań prowadzonych w Pracowni działań i struktur wizualnych w latach 1971-72. Wrocław 1972.

A. Lachowicz, Perswazja wizualna i mentalna. Wrocław 1972.

A. Lachowicz, Obserwacje i notacje. Warszawa 2008.

J. Lewczyński, Fotografie i rzeczy znalezione. Wrocław 2007.

D. Mersch, Teorie mediów. Przeł. E. Krauss. Warszawa 2010.

M. McLuhan, Wybór tekstów, przeł. E. Różalska, J. M. Stokłosa, Poznań 2001.

J. Olek, O..., Poznań 2013.

M. Poprawska, Światłoforma. Ksiq̨żka dla fotografii. Materiały z archiwum M. Poprawskiej, Poznań 1999.

S. Wojnecki, Fotografia gwiazda podwójna kultury. Pisma z lat 1977-2004. Poznań 2007.

E. Wójtowicz, Sztuka w kulturze postmedialnej, Gdańsk 2016.

Linkografia G. Crewdson, Beneath the Roses, online, http://www.gregorycrewdsonmovie.com/ (dostęp: 10.09.2017). S. Decyk, Cyklografie, online, http://fotografia.uap.edu.pl/wykladowcy/ decyk-slawomir/ (10.09.2017). Z. Dłubak, Asymetrie, online, http://faf.org.pl/image/tid/353 (dostęp10.09.2017).

P. Kula, Narzędzia i eksperymenty, online, http://pawelkula.blogspot.com/p/zabaw.html (dostęp 10.09.2017). S. Meisalas, Kurdistan, online, http://www.susanmeiselas.com/archive-projects/ kurdistan/\#id=intro (10.09.2017).

\section{Filmografia}

J. Meyerowitz, wypowiedź w filmie: Ch. Dunn, Nowojorska ulica w obiektywie. Stany Zjednoczone 2013. 


\section{Streszczenie:}

$\mathrm{W}$ artykule przedstawione są cztery programy fotografii artystycznej związane z refleksją nad mediami. W pierwszej części opisana jest relacja fotografii i tzw. pre-mediów, charakterystycznych postrzeganiu, tj. światło, powietrze. $\mathrm{W}$ drugim rozdziale przedstawiony jest związek między ziarnistą strukturą fotograficzną a teorią pola równomiernego będącą u podstaw wiedzy z zakresu kompozycji wizualnej oraz kreacji znaków. W trzeciej części fotografia opisana jest na tle rozwoju cyfrowej technologii wpływającej zasadniczo na zmianę procesu powstawania zdjęć. Ostatni rozdział dotyczy związków fotografii z mediami społecznymi rozumianymi jako specyficzna więź łącząca ludzi używających zdjęć w celach komunikacyjnych.

Słowa klucze: pre-media, struktura fotograficzna, znak, stare i nowe media, media społeczne

\section{Photography in epistemological doctrine}

\section{Summary:}

The article presents four programmes of artistic photography related to the reflection on media. The initial part is devoted to the specificity of relationship between photography and the so called pre-media, characterized by perception, that is light, air. The second chapter presents the relationship between photographic grain structure and the uniform field theory which forms the basis of knowledge in the scope of visual composition and creation of signs. Within the third part, the photography is described at the background of the development of digital technology impacting substantially the change of process of picture creation. The final chapter concerns relations between photography and the social media, understood as a specific bond linking people who avail of photographs for communication purposes.

Keyword: pre-media, photographic structure, sign, old and new media, social media 